\title{
Comunicação
}

[Communication $]$

\section{Tétano em pequenos ruminantes: estudo retrospectivo dos principais achados clínico-epidemiológicos em 11 casos}

\author{
[Tetanus in small ruminants: retrospective study of major clinical and epidemiological \\ findings in 11 cases]
}

\author{
A.C.S. Almeida, M.G. Ribeiro*, A.C. Paes, J. Megid, V.B. Oliveira, M.M.J. Franco
}

Faculdade de Medicina Veterinária e Zootecnia -UNESP/Botucatu, SP

O tétano é reconhecido como doença toxiinfecciosa aguda, altamente letal, que acomete humanos e animais domésticos, causada pela ação de potente neurotoxina produzida pelo Clostridium tetani (Lobato et al., 2007).

C. tetani é bactéria anaeróbica estrita. Possui origem telúrica, podendo se apresentar sob a forma vegetativa ou esporulada, dependendo das condiçõos de tensão de oxigênio local. A forma esporulada da bactéria possui alta resistência ambiental, mantendo-se viável em diferentes condições adversas, que incluem extremos de temperatura e exposição à luz solar direta. Os esporos são encontrados em áreas cultiváveis, ricas em matéria orgânica, em pastos explorados para a criação de animais de produção e nas fezes de animais e humanos (Quinn et al., 2005).

A doença possui distribuição mundial. Acomete todas as espécies de animais domésticos, embora os equinos sejam reconhecidamente mais susceptíveis, seguidos pelos ovinos, caprinos e suínos, enquanto nos bovinos, cães e gatos a doença é ocasional (Ribeiro et al., 2000; Smith, 2006).

A porta de entrada da bactéria comumente está relacionada a traumatismos por objetos perfurocortantes, cirurgias ou qualquer procedimento que propicie baixa tensão de oxigênio tecidual. Estas condições tissulares desencadeiam a modulação da forma esporulada de $C$. tetani para a forma vegetativa e a liberação

Recebido em 24 de maio de 2011

Aceito em 16 de abril de 2012

*Autor para correspondência (corresponding author)

E-mail: mgribeiro@fmvz.unesp.br das toxinas tetanolisina e tetanospasmina, sendo a última caracterizada como potente neurotoxina relacionada às manifestações clínicas da doença. C. tetani não possui capacidade invasora, ficando restrita ao foco de infecção (Corrêa e Corrêa, 1992; Radostits et al., 2007).

Dentre os fatores ou procedimentos considerados predisponentes no estabelecimento do tétano em ruminantes domésticos, merecem destaque as vulnerações em diferentes regiões corpóreas, contaminação umbilical, da genitália e da placenta no período pós-parto, cirurgias (castração, caudectomia, descorna, ováriohisterectomia), vacinações e tosquia (Pugh, 2004; Smith, 2006).

O período de incubação varia entre três dias a quatro semanas. Os sinais clínicos em animais de produção iniciam com aumento de rigidez muscular, acompanhada por tremor. Ocorre trismo com limitação de movimentos da mandíbula, prolapso de terceira pálpebra, rigidez de membros posteriores, cauda rígida $\mathrm{e}$ deslocada do corpo, posicionamento ereto das orelhas, dilatação das narinas, hiperestesia e resposta exagerada aos estímulos externos. À medida que a doença progride, o animal assume "posição de cavalete" (Pugh, 2004; Radostits et al., 2007). Comumente, o diagnóstico é clínico. Exames clínico-laboratoriais subsidiários geralmente não são conclusivos na doença (Smith, 2006). O prognóstico é sempre reservado, e a gravidade dos casos é inversamente proporcional ao período de incubação (Corrêa e Corrêa, 1992). 
A maioria das descrições de tétano em pequenos ruminantes, em outros países e no Brasil (Aslani et al., 1998), está restrita a relatos de caso e, ocasionalmente, envolve vários animais (Driemeier, 2007). Em virtude da escassez de estudo do tétano em pequenos ruminantes envolvendo vários animais, investigaram-se os principais achados clínicos e epidemiológicos em 11 casos de tétano em ovinos e caprinos.

Foram avaliados 11 casos de tétano em pequenos ruminantes, atendidos no serviço ambulatorial de Enfermidades Infecciosas dos Animais da FMVZ-UNESP/Botucatu, SP, durante período de dez anos, compreendido entre 1998 e 2008 . Na anamnese dos animais, foram investigados dados relativos à idade, sexo, raça, mês de ocorrência, histórico de lesões, procedimentos cirúrgicos e/ou de manejo. Foram avaliados, também, os principais sinais clínicos, período de evolução do início dos sinais até o atendimento, período de hospitalização e letalidade.

Em todos os animais, foi realizado tratamento padrão, constituído da administração de soro antitetânico (100.000UI, via intravenosa, dose única), penicilina benzatina (20 a $40.000 \mathrm{UI} / \mathrm{kg}$, via intramuscular, dose única). Foi realizada terapia de suporte, que incluiu correção tanto do equilíbrio hidroeletrolítico quanto do energético (soluções à base de ringer com lactato, bicarbonato e glicose), relaxante muscular (Diazepam 0,5 a 1,5/mg/kg/IM ou IV/TID), higienização com peróxido de hidrogênio e iodo (1\%), nos animais com ferimentos aparentes, e cateterização vesical. Os animais foram mantidos em baias isoladas, escuras, em local de baixo ruído e de acesso restrito. No decurso do tratamento, quando os animais adotaram posição de decúbito, foram mantidos em colchão apropriado, com alteração diária do posicionamento, evitando-se a ocorrência de escaras de decúbito e pneumonia por hipostase. O diagnóstico de tétano foi fundamentado na anamnese dos animais e nos sinais clínicos característicos da doença.
A Tab. 1 resume os principais achados clínico-epidemiológicos nos 11 casos de tétano em pequenos ruminantes. Os casos foram observados em oito ovinos e três caprinos de diferentes raças ou mestiços. A doença foi identificada em animais entre cinco dias e cinco anos. O predomínio dos casos foi observado entre as primeiras semanas e dois anos de idade, em sete animais $(63,0 \%)$. Foi constatada maior ocorrência da doença no período de inverno, observada em oito animais $(72,0 \%)$ entre os meses de junho e agosto. Ferimentos ou histórico de procedimentos de manejo ou cirúrgicos foram verificados em oito animais $(72,0 \%)$, apresentando-se, principalmente, com presença de infecções umbilicais, seguidas por distúrbios do periparto e cirurgias/procedimentos de rotina (caudectomia, castração e descorna). Em três animais nos quais não foi possível o reconhecimento de lesões, o período de incubação variou entre sete e 21 dias. O período entre o início dos sinais e o atendimento dos animais oscilou entre um e sete dias, com maior frequência de atendimento dos animais no primeiro dia de início das manifestações clínicas. A letalidade foi verificada na totalidade dos animais. $\mathrm{O}$ período de hospitalização, na maioria dos animais, não excedeu o primeiro dia. A principal complicação clínica observada nos animais ao longo do tratamento foi $o$ desenvolvimento de pneumonia.

As manifestações clínicas observadas nos 11 animais foram: rigidez muscular de membros anteriores e/ou posteriores (54,5\%), dificuldade de locomoção (54,5\%), taquipneia/dispneia $(54,5 \%)$, alteração de posicionamento de orelhas ("orelhas em tesoura") $(45,4 \%), \quad$ trismo mandibular $(36,3 \%)$, sialorreia $(36,3 \%)$, congestão de mucosas $(36,3 \%)$, posição de "cavalete" $(27,2 \%)$, protrusão de terceira pálpebra $(27,2 \%)$, opistótono $(27,2 \%)$, "cauda em bandeira" $(18,1 \%)$ e hipersensibilidade a estímulos externos $(18,1 \%)$. 
Tabela 1. Principais achados clínico-epidemiológicos em 11 casos de tétano em pequenos ruminantes. Botucatu, SP, 1998-2008

\begin{tabular}{|c|c|c|c|c|c|c|c|c|}
\hline Animal & Idade & Sexo & Raça & Espécie & $\begin{array}{l}\text { Mês e Ano } \\
\text { de } \\
\text { ocorrência }\end{array}$ & $\begin{array}{c}\text { Fatores } \\
\text { predisponentes ou } \\
\text { de risco (dias antes } \\
\text { do início dos } \\
\text { sinais) }\end{array}$ & $\begin{array}{l}\text { Período de } \\
\text { evolução dos } \\
\text { sinais até o } \\
\text { atendimento } \\
\text { (dias) }\end{array}$ & $\begin{array}{c}\text { Recuperação ou } \\
\text { óbito e período } \\
\text { de } \\
\text { hospitalização } \\
\text { (dias) }\end{array}$ \\
\hline 1 & 2 anos & $\mathrm{F}$ & $\begin{array}{l}\text { Santa } \\
\text { Inês }\end{array}$ & Ovino & $\begin{array}{c}\text { Junho de } \\
1998\end{array}$ & $\begin{array}{c}\text { Parto } \\
(7 \text { dias })\end{array}$ & 7 & $\begin{array}{l}\text { Óbito } \\
\text { (1 dia) }\end{array}$ \\
\hline 2 & - & $\mathrm{F}$ & Mestiça & Ovino & $\begin{array}{c}\text { Agosto de } \\
1998\end{array}$ & Ausência de ferida & 2 & $\begin{array}{l}\text { Óbito } \\
\text { (1 dia) }\end{array}$ \\
\hline 3 & 1 mês & M & Suffolk & Ovino & $\begin{array}{l}\text { Agosto de } \\
1998\end{array}$ & Onfaloflebite & 1 & $\begin{array}{l}\text { Óbito } \\
\text { (1 dia) }\end{array}$ \\
\hline 4 & 4 anos & $\mathrm{F}$ & Mestiça & Ovino & $\begin{array}{l}\text { Novembro } \\
\text { de } 2000\end{array}$ & $\begin{array}{l}\text { Abortamento } \\
\text { (15 dias) }\end{array}$ & 1 & $\begin{array}{l}\text { Óbito } \\
\text { (1 dia) }\end{array}$ \\
\hline 5 & 1 ano & $\mathrm{F}$ & Saanem & Caprino & $\begin{array}{l}\text { Março de } \\
2001\end{array}$ & Descorna (1 dia) & 1 & $\begin{array}{l}\text { Óbito } \\
\text { (2 dias) }\end{array}$ \\
\hline 6 & 5 anos & $\mathrm{F}$ & SRD & Caprino & $\begin{array}{l}\text { Junho de } \\
2001\end{array}$ & Ausência de ferida & 1 & $\begin{array}{l}\text { Óbito } \\
\text { (1 dia) }\end{array}$ \\
\hline 7 & 1 ano & M & Mestiço & Ovino & $\begin{array}{l}\text { Agosto de } \\
2001\end{array}$ & $\begin{array}{c}\text { Castração } \\
\text { (21 dias) }\end{array}$ & 3 & $\begin{array}{l}\text { Óbito } \\
\text { (7 dias) }\end{array}$ \\
\hline 8 & 5 dias & M & Mestiço & Ovino & $\begin{array}{l}\text { Junho de } \\
2002\end{array}$ & Onfaloflebite & - & $\begin{array}{l}\text { Óbito } \\
\text { (1 dia) }\end{array}$ \\
\hline 9 & 3 meses & $\mathrm{F}$ & Suffolk & Ovino & $\begin{array}{c}\text { Julho de } \\
2002\end{array}$ & $\begin{array}{l}\text { Caudectomia } \\
\text { (8 dias) }\end{array}$ & 3 & $\begin{array}{l}\text { Óbito } \\
\text { (2 dias) }\end{array}$ \\
\hline 10 & 8 dias & M & $\begin{array}{l}\text { Ile de } \\
\text { France }\end{array}$ & Ovino & $\begin{array}{c}\text { Outubro de } \\
2002\end{array}$ & Onfaloflebite & 1 & $\begin{array}{l}\text { Óbito } \\
\text { (12 dias) }\end{array}$ \\
\hline 11 & $\begin{array}{l}2 \text { anos e } \\
8 \text { meses }\end{array}$ & $\mathrm{F}$ & Saanem & Caprino & $\begin{array}{c}\text { Julho de } \\
2004\end{array}$ & Ausência de ferida & 1 & $\begin{array}{l}\text { Óbito } \\
\text { (2 dias) }\end{array}$ \\
\hline
\end{tabular}

Os casos de tétano em ovinos e caprinos foram descritos em propriedades distintas, confirmando a ocorrência esporádica da doença em pequenos ruminantes, geralmente sob a forma de casos isolados (Pugh, 2004). A presença da doença em animais machos ou fêmeas, de diferentes raças ou mestiços, reforça que estes fatores provavelmente exercem pouca influência na ocorrência do tétano em pequenos ruminantes (Guedes et al., 2007). O predomínio da doença nos meses que caracterizam a estação do inverno pode ser justificado pela aglomeração dos animais em piquetes ou próximos a cochos neste período de escassez de alimentos, ou mesmo em decorrência do recolhimento dos animais para o interior dos apriscos no período noturno (Carvalho et al., 2008), o que poderia favorecer traumatismos e a ocorrência da doença.

A alta ocorrência de tétano nos animais estudados, entre as primeiras semanas e os dois anos de idade, também foi observada por Guedes et al. (2007) em 10 casos descritos em ovinos e caprinos do semiárido do Brasil. Este achado pode ser creditado à intensificação dos procedimentos de manejo nesta faixa etária - os quais incluem descorna, descola, castração, aplicação de brincos, vacinações - considerados predisponentes no estabelecimento do tétano em ovinos e caprinos (Pugh, 2004; Radostits et al., 2007). O reconhecimento de lesões e/ou procedimentos lesivos pregressos ao início das manifestações clínicas, observados em oito animais, corrobora a maioria dos relatos de tétano em pequenos ruminantes, frequentemente relacionados a traumatismos, procedimentos cirúrgicos (caudectomia, castração e descorna), bem como a infecções umbilicais e distúrbios do puerpério, que favorecem a contaminação telúrica por esporos do micro-organismo (Pugh, 2004; Smith, 2006; Guedes et al., 2007).

O período de incubação entre sete e 21 dias foi observado em três animais, nos quais foi possível a identificação de lesões/procedimentos anteriores ao início das manifestações clínicas. Este período variável de incubação da doença, geralmente entre três dias e quatro semanas, é similar ao referido por outros autores (Pugh, 2004; Smith, 2006; Guedes et al., 2007) e está intimamente relacionado à carga infectante bacteriana e à capacidade de produção de toxina por C. tetani (Quinn et al., 2005).

Rigidez muscular em membros, contrações musculares, dificuldade de locomoção, taquicardia, taquipneia, alterações no posicionamento de orelhas, trismo mandibular 
foram os sinais clínicos mais frequentemente observados nos 11 animais, seguidos em menor frequência por "posição de cavalete", protrusão de terceira pálpebra, opistótono, elevação da cauda e hipersensibilidade a estímulos externos. Tais achados também têm sido relatados por outros autores, apesar de variações de intensidade e frequência (Corrêa e Corrêa, 1992; Pugh, 2004; Smith, 2006; Driemeier et al., 2007; Guedes et al., 2007). Estes sinais são considerados característicos da doença, possibilitando o diagnóstico clínico, aliado aos dados epidemiológicos, na grande maioria dos casos de tétano em pequenos ruminantes.

Mesmo diante da prescrição do tratamento nos 11 animais com base nos preceitos fundamentais recomendados na terapia da doença (Corrêa e Corrêa, 1992; Pugh, 2004; Smith, 2006; Radostits et al., 2007), em nenhum dos casos foi obtida a cura. Guedes et al. (2007), ao investigarem doenças com comprometimento do sistema nervoso central em pequenos ruminantes da região do semiárido no Brasil, descreveram 10 casos de tétano, em oito caprinos e dois ovinos, do qual também nenhum dos animais recuperouse, mesmo com o tratamento. A alta letalidade do tétano em equinos, ovinos e caprinos é atribuída à maior susceptibilidade destas espécies aos efeitos da toxina produzida por $C$. tetani (Radostits et al., 2007) ou ao desenvolvimento de pneumonia e cólicas, que podem complicar a evolução dos casos.

Nos 11 animais estudados, inferiu-se a presença de casos isolados de tétano nos criatórios, com predomínio nos meses de inverno em animais de até dois anos de idade, geralmente relacionados ao histórico de traumatismos, procedimentos cirúrgicos ou de rotina no manejo de ovinos e caprinos, considerados predisponentes para a afecção. A alta letalidade da doença reforça a necessidade de adoção de boas práticas de manejo, higiene e vacinação dos pequenos ruminantes na prevenção do tétano nos criatórios.

Palavra-chave: tétano, Clostridium tetani, ovinos, caprinos

\begin{abstract}
A retrospective study of major clinical and epidemiological findings was performed in 11 cases of tetanus observed in eight sheep and three goats from 1998 to 2008. The cases occurred predominantly in animals aging from five days to two years, in winter season, with history of recent wounds or surgical procedures. Muscle rigidity and muscular tremors (72.0\%), tachycardialdyspnea (54.5\%), change of placement of ears (45.4\%), protusion of the third eyelid (27.2\%), hypersensitivity to external stimulus (18.1\%), and elevation of ears $(18.1 \%)$ were the most common clinical signs.
\end{abstract}

Keywords: tetanus, sheep, goat, epidemiology, clinical signs, Clostridium tetani

\section{REFERÊNCIAS}

ASLANI, M.R.; BAZARGANI, T.T.; ASHKAR, A.A. et al. Outbreak of tetanus in lambs. Vet. Rec., v.142, p.29-38, 2007.

CARVALHO, E.B.; OLIVEIRA, M.A.G.; DOMINGUES, P.F. Base para a criação de ovinos do estado de São Paulo. Associação Paulista de Criadores de Ovinos-ASPACO, 2008.

CORREA, W.M.; CORREA, C.N.M. Enfermidades Infecciosas dos Animais Domésticos. 2.ed. São Paulo: Medsi, 1992. 843p.
DRIEMEIER, D.; SCHILD, A.L.; FERNANDES, J.C.T. et al. Outbreaks of Tetanus in beef catte and sheep in Brazil associated with disophenol injection. $J$. Vet. Med. Series A, v.54, p.333-335, 2007.

GUEDES, K.M.R.; RIET-CORREA, F.; DANTAS, A.F.M. et al. Doenças do sistema nervoso central em caprinos e ovinos no semi-árido. Pesq. Vet. Bras., v.27, p.29-38, 2007.

LOBATO, F.C.F.; ASSIS, R.A.; SALVARANI, F.M. Clostridioses dos Pequenos Ruminantes. Rev. Port. Cienc. Vet., v.102, p.23-34, 2007. 
PUGH, D.G. Clínica de Ovinos e Caprinos. 1.ed. São Paulo: Roca, 2004. 513 p.

QUINN, P.J.; CARTER, M.E.; MARKEY, B.K.; CARTER, G.R. Microbiologia Veterinária e Doenças Infecciosas. 1.ed. Porto Alegre: Artmed, 2005. 512p.

RADOSTITS, O.M.; GAY, C.C.; HINCHCLIFF, K.W.; CONSTABLE, P.D. Clínica Veterinária: Um tratado de doenças dos bovinos, ovinos, suínos, caprinos e equinos. 8.ed. Rio de Janeiro: Guanabara Koogan, 2007. 1737p.
RIBEIRO, M.G.; MEGID, J.; PAES, A.C.; BRITO, C.J.C. Canine tetanus: clinical-epidemiological study. Rev. Bras. Med. Vet., v.22, p.58-62, 2000.

SMITH, B.P. Medicina Interna de Grandes Animais. 3.ed. São Paulo: Manole, 2006. 1728 p. 